\title{
Autonomic vulnerability to biased perception of social inclusion in borderline personality disorder
}

\author{
Maria Lidia Gerra ${ }^{1 *}$, Martina Ardizzi ${ }^{2}$, Silvia Martorana ${ }^{2}$, Veronica Leoni ${ }^{2}$, Paolo Riva ${ }^{3}$, Emanuele Preti ${ }^{3}$, \\ Barbara Francesca Marta Marino ${ }^{3}$, Paolo Ossola ${ }^{2}$, Carlo Marchesi ${ }^{2}$, Vittorio Gallese ${ }^{2}$ and Chiara De Panfilis ${ }^{2}$
}

\begin{abstract}
Background: Individuals with Borderline Personality Disorder (BPD) feel rejected even when socially included. The pathophysiological mechanisms of this rejection bias are still unknown. Using the Cyberball paradigm, we investigated whether patients with BPD, display altered physiological responses to social inclusion and ostracism, as assessed by changes in Respiratory Sinus Arrhythmia (RSA).

Methods: The sample comprised 30 patients with BPD, 30 with remitted Major Depressive Disorder (rMDD) and 30 Healthy Controls (HC). Self-report ratings of threats toward one's fundamental need to belong and RSA reactivity were measured immediately after each Cyberball condition.

Results: Participants with BPD showed lower RSA at rest than HC. Only patients with BPD, reported higher threats to fundamental needs and exhibited a further decline in RSA after the Inclusion condition.

Conclusions: Individuals with BPD experience a biased appraisal of social inclusion both at the subjective and physiological level, showing higher feelings of ostracism and a breakdown of autonomic regulation to including social scenarios.
\end{abstract}

Keywords: Respiratory sinus arrhythmia, Rejection bias, Cyberball paradigm, Polyvagal theory

\section{Background}

Borderline Personality Disorder (BPD) is a severe mental illness affecting approximately $1 \%$ of the general population [1]. Social dysfunction represents one of the most enduring and challenging to treat feature of the disorder, which is not substantially affected by a symptomatic decrease or even remission over time [2]. In BPD, social impairment is fostered by a unique interpersonal hypersensitivity pattern, encompassing extensive preoccupation with real or imagined abandonment and rejection, and related distrustful perceptions of others as bad, malevolent, and excluding [3-5]. Therefore, clarifying the

\footnotetext{
* Correspondence: magerra@ausl.pr.it

${ }^{1}$ Department of Mental Health, AUSL of Parma, Parma, Italy

Full list of author information is available at the end of the article
}

potential mechanisms fostering this peculiar way of processing interpersonal cues is a primary clinical and research goal in BPD study.

\section{Rejection bias in BPD}

Recent studies evaluated BPD patients' responses to varying degrees of interpersonal inclusion using Cyberball, a virtual ball-tossing game where participants can be socially excluded, included, or even over-included by others [6, 7]. Results indicate that patients with BPD do not merely "over-react" to actual social exclusion; rather, they feel rejected and experience greater rejectionrelated negative emotions than controls following objective interpersonal inclusion [8-10]. Moreover, individuals with BPD feel disconnected from others even when they 
face a condition of extreme interpersonal inclusion [11, 12]. Overall, these findings suggest a "misperception of social participation": patients with BPD show biased processing of social inclusion, which makes them perceive rejection even in interpersonal situations that are objectively including.

\section{Autonomic correlates of rejection bias in BPD}

To date, most BPD studies focused on subjective (i.e., explicit, self-reported) emotional reactions to the Cyberball experiment, while the underlying implicit pathophysiological mechanisms of this rejection bias are yet to be fully elucidated.

The Polyvagal Theory [13] provides a theoretical framework to study the Autonomic Nervous System (ANS) reactivity to perceived threatening interpersonal cues. According to such theory, the myelinated vagal system evolved to support flexible adaptation to environmental stimuli. When the environment is appraised as safe, at the cardiac level, the "vagal brake" increases the parasympathethic activity on the hearth, slows down the heart rate, and inhibits the more primitive ANS systems (i.e., the sympathetic nervous system and the unmielynated vagus) that promote fight/fly or freeze defense strategies. Ultimately, this serves to support effective social engagement behaviors. In this way, prosocialaffiliative interactions can adaptively emerge and persist over time in safe contexts.

The dynamic functional impact of the myelinated vagal fibers on the heart is reflected by the amplitude of the Respiratory Sinus Arrhythmia (RSA), a naturally occurring rhythm in the cardiac cycle at approximately the frequency of spontaneous breathing [14-16]. Thus, measurement of the amplitude of RSA provides an assessment of the state of the vagal brake: increased vagal influence on the heart corresponds to high or increased RSA. By contrast, in challenging or threatening situations, the vagal brake is withdrawn, leading to physiological states that support the fight, flight, or freeze behaviors but inhibiting social engagement behaviors. This vagal withdrawal is reflected in RSA decreases. Thus, high RSA at rest and in safe environments and the appropriate RSA suppression in the face of real environmental risks represent a marker of successful selfregulation. Notably, this flexible and adaptive increase or decrease in RSA crucially depends on the environmental risks' accurate appraisal.

The neural ability to distinguish environmental features that are safe, dangerous, or life-threatening is called neuroception, a process of neural detection of risk that does not require conscious awareness [13]. When neuroception is impaired, the ANS fails to distinguish between safe and dangerous contexts accurately: thus, the environment may be appraised as dangerous when it is safe. This leads to a mismatch between the actual risk of the environment and the neurophysiological state, resulting in an inability to appropriately inhibit the defense systems and maintain prosocial behaviors in safe environments. It is possible to measure such mismatch by assessing RSA both at rest and during various environmental challenges: low RSA in the absence of environmental demands or in response to stimuli that are not threatening would suggest that individuals physiologically appraise and react to safe environments as if they were actually unsafe [13].

In this regard, accumulating evidence indicates that patients with BPD exhibit low cardiac vagal tone at rest [17-21], indicating that they present a constant physiological condition of preparedness to face threats and danger. In the same vein, having low RSA at rest mediates the association between BPD symptoms and reactive aggression in a non-clinical population [22], suggesting that impaired vagal control leads to maladaptive social behaviors in individuals with BPD features.

Three other studies on BPD examined RSA reactivity, that is, RSA change in response to various experimental stimuli, like film clips of varying emotional content [23], mental arithmetic tasks [18], and standardized film and idiographic imagery paradigms [17]. Overall, these studies found that, among participants with BPD, RSA remained as low as at baseline [17] or even decreased during the experiment $[18,23]$. These studies suggest that engaging in an emotional or cognitive experimental task induces, among patients with BPD, a physiological state that promotes defensive behaviors, with phylogenetically older 'fight-or-flight' response, rather than a visceral state that supports self-regulation and spontaneous social engagement behaviors.

To our knowledge, no study yet evaluated RSA reactivity in response to varying degrees of social inclusion in BPD. Such inquiry could clarify whether BPD patients subjectively perceive including social scenarios as if they were rejecting by reacting to them with a breakdown of the self-regulation and socialization capacities, rooted in the myelinated vagal system's activity.

It is also important to examine whether such hypothesized in including situations, associated with vagal withdrawal, truly represents a BPD-specific alteration, by comparing BPD with a clinical and medicated control group, with similar illness duration. In this regard, patients with Major Depressive Disorder (MDD) have also been found to exhibit peculiar responses to the Cyberball experiment and altered RSA patterns as compared with Healthy Controls (HC).

As compared with $\mathrm{HC}$, patients with active MDD (i.e., during full-blown depressive episodes) experience a greater sense of threat to psychological fundamental needs after social exclusion [24-29]. Interestingly, 
although one study also found that MDD patients report greater perception of threat after social inclusion than $\mathrm{HC}$ [30], another study argued that such rejection bias in including situations among patients with active MDD was explained by BPD comorbidity [31]. Only one study evaluated how patients with MDD in the remission phase (rMDD) react to the Cyberball experiment [32]. However, this study assessed social distress related to the task as a whole, and not after the inclusion and ostracism conditions. Thus, it is not known yet whether the increased sensitivity to ostracism (and possibly the rejection bias) showed by MDD patients during an active depressive episode would persist even in the euthymic phase, thus representing a trait-based phenomenon rather than just a state-dependent phenomenon that is apparent only during full-blown episodes.

With respect to RSA findings, patients with active MDD were found to exhibit low resting RSA and atypical RSA reactivity to various laboratory stressors. Further, during the remission phase patients with MDD exhibit low resting RSA but not altered RSA reactivity to laboratory tasks [33-38]. Thus, low RSA at rest seems to represent a stable, trait-like feature of MDD, which persists even during the euthymic phase, when patients with rMDD may still exhibit distinctive clinical features, such as subthreshold psychopathology [35], peculiar personality styles [36], or symptomatological scars of previous episodes [37]. Conversely, altered RSA reactivity during active phases of depression is likely to represent a state-effect of full-blown depressive psychopathology [34]. However, no study yet measured RSA reactivity to Cyberball in MDD.

Thus, it is not yet clear whether MDD patients exhibit peculiar patterns of responses to Cyberball associated with altered RSA reactivity, which persist at the remission of depressive episodes.

Therefore, in this study we compared BPD patients, with no current depressive episode, with rMDD patients on maintenance treatment, with no BPD comorbidity, to investigate whether RSA alterations following the Cyberball conditions could represent a stable, trait-like element that could distinguish the clinical groups, over and above the confounding effect of full-blown depressive symptomatology. Importantly, such comparison also allows for controlling for the potential confounding effect of sub-threshold depressive symptoms. Patients with BPD often present with depressive symptoms, although known to be transient, stress reactive and arising from a primary diagnosis of BPD $[39,40]$; in the same vein, patients with rMDD also may experience inter-episodic depressive psychopathology [35].

\section{The present study}

This study investigated whether patients with BPD, compared to $\mathrm{HC}$ and patients with $\mathrm{rMDD}$, show an altered emotional response associated with an altered vagal reactivity after Cyberball conditions of Social Inclusion and Ostracism, as well as $10 \mathrm{~min}$ after Ostracism (Reflective stage). Based on previous research, three main predictions guided our investigation.

First, we expected to replicate the finding that BPD patients, compared to healthy and clinical controls, would report reduced levels of satisfaction of fundamental psychological needs (e.g., the need to belong) even in including situation both immediately after Ostracism, as well as at the Reflective stage. This would confirm a biased perception of social inclusion at the subjective (i.e., explicit) level in BPD.

Second, we expected that patients with BPD, compared to healthy and clinical controls, would exhibit reduced RSA at rest (i.e., before starting the game), indicating stable difficulties in social predisposition at the physiological level. Moreover, we expected that at the ANS level, patients with BPD would show a further decrease in RSA after the Cyberball Inclusion condition than baseline RSA. This would indicate that individuals with BPD physiologically respond to including social situations as if they were threatening, with a dysfunctional withdrawal of the vagal brake that leads to increased physiological arousal, mobilizing defensive reactions but impeding successful social engagement.

Finally, we hypothesized that a higher perception of threat to fundamental psychological needs induced by the Cyberball task would be associated with higher physiological arousal as indicated by vagal withdrawal (i.e., a more substantial decline in RSA).

\section{Methods}

\section{Participants}

This study involved 30 patients with BPD, 30 patients with rMDD, and $30 \mathrm{HC}$. Patients were recruited at the psychiatry outpatient services of Parma Local Health Agency (Parma, Italy) from January 2016 to September 2018. HC, matched for age and gender with patients with BPD, were recruited through advertisements in meeting places in the local community.

\section{Inclusion and exclusion criteria}

Inclusion criteria were: 1) age 18-65 years; 2) native Italian speaker or proficient in Italian; 3) for the clinical groups, meeting the diagnostic criteria for rMDD or BPD, assessed by the Structured Clinical Interview for DSM-5 disorders, Clinician Version (SCID-5-CV) [41] and the Structured Clinical Interview for DSM-5 Personality Disorders (SCID-5-PD) [42], respectively; 4) scoring $<7$ on the 21-item Hamilton Rating Scale for Depression (HAM-D) [43] and $<7$ in the Hamilton Anxiety Rating Scale (HAM-A) [44]. 
Exclusion criteria were: 1) any cardio-respiratory diseases and treatment that directly affect the ANS's function (e.g., sympatho-mimetic and para-sympathomimetic drugs, alpha and beta receptors blockers, and anti-muscarinic drugs); 2) cognitive impairment, assessed by the Wechsler Adult Intelligence Scale Matrix Reasoning Subtest [45]; 3) any current diagnoses of Schizophrenia spectrum and other Psychotic Disorders, Bipolar Disorders, Anxiety Disorders, Post-Traumatic Stress Disorder, Somatic Symptom and related Disorders and Eating Disorders. For the BPD group, both current and lifetime MDD comorbidity also was an exclusion criterion. However, for both clinical groups, we included patients with other previous lifetime disorders, though fully remitted at the study time (i.e., Adjustment disorders, Substance-related disorders, Eating Disorders, Obsessive-Compulsive Disorder). Patients were not excluded for regular psychotropic medication use.

Participants were told that the researchers were investigating "Mental visualization and individual differences in heart rate and psychological responses." This cover story is thought to maximize the experiment's ecological validity [46]. Participants gave written informed consent to participation and, after completion of the experiment, were extensively debriefed and given detailed information about the study and its purposes, with the opportunity to have their data deleted should they wish so.

The total sample size collected $(N=90)$ exceeded the minimum amount required $(N=54)$ estimated using a priori sample size calculation, obtained for repeatedmeasures analyses of variance (ANOVA) considering both within and between interactions $(1-\beta=.95, \alpha=.05$, effect size $F=.25)$. The sample size was computed with G* power [47] based on the effect size of previous studies that compared BPD with two other clinical groups [48]. We enlarged the a-priori required sample size up to 30 per group to account for covariates, such as age, Body
Mass Index (BMI), alcohol and tobacco consumption, known to affect RSA.

\section{Psychometric assessment}

All participants completed a general demographic questionnaire on age, gender, BMI, physical activity, educational level, occupational and marital status, and habitual consumption of psychotropic substances (alcohol, caffeine, and nicotine).

Psychosocial functioning was assessed with the Global Assessment of Functioning Scale (GAF) [49].

\section{Experimental procedure}

Participants were led into a quiet and soft illuminated room and were instructed to relax and remain seated comfortably. At the beginning of the experimental session, participants were instructed to sit quietly with their eyes open, and a 2-min resting baseline electrocardiogram (ECG) was recorded to assess RSA at rest.

Subsequently, they participated in a Cyberball experiment and completed different measures of their current emotional state. ECG recordings were collected over the entire duration of the experimental session to extract phasic autonomic measures (i.e., RSA reactivity). Please refer to Fig. 1 for a graphical display of the experimental procedure.

\section{Cyberball experiment}

Inclusionary status was manipulated using a classic paradigm called Cyberball (Cyberball (version 4.0) [Software] available from https://cyberball.wikispaces.com). This virtual ball-tossing game has been developed to induce feelings of ostracism in controlled settings [7]. Following the typical procedure [46], participants were told that investigators were interested in the effects of mental visualization on a subsequent task and that a good way to warm up was to engage in a mental visualization exercise with other online players. In actuality, these two

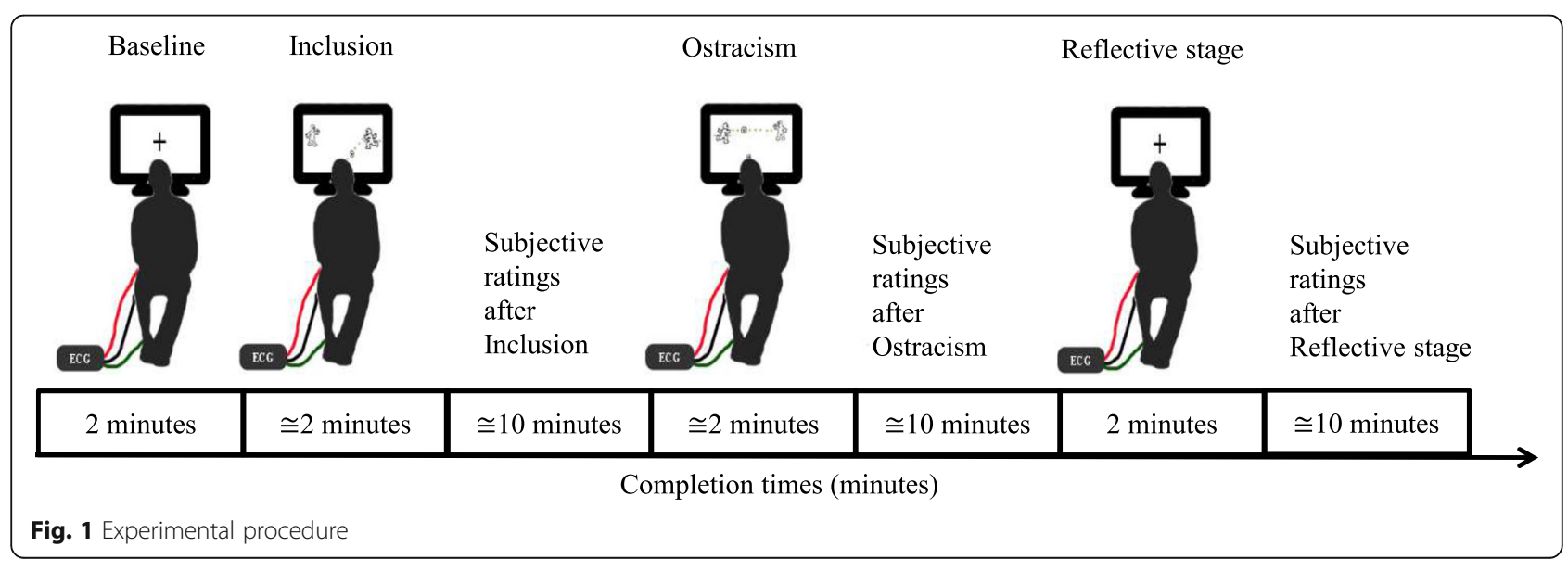


other players were not real; instead, they were computer-controlled confederate players, identified using a name. All participants were enrolled in two consecutive conditions of the Cyberball game: initially, they were included in a belonging game (i.e., receiving the ball about a third of the time, roughly $33 \%$ of the total throws) and then ostracized (i.e., receiving the ball once from each computer-controlled player and then never again, roughly $10 \%$ of the total throws). The order of the Inclusion-Ostracism conditions was kept fixed for all participants (for a similar procedure, see: [50]).

\section{Manipulation checks}

After each Cyberball condition, participants rated the percentage of throws $(0-100 \%)$ they received during the game as a manipulation check. They were then asked to report how excluded ("I felt excluded") and ignored ("I felt ignored") they felt during each Cyberball session. Responses were rated on 10-point scales (ranging from $1=$ not at all to $10=$ very much). The two items were combined in an overall index of feelings of being excluded and ignored. Higher scores indicate greater feelings of ostracism.

\section{Subjective responses to the Cyberball game}

Participants were asked to report their feelings three times: after Cyberball Inclusion, immediately after Cyberball Ostracism, and $10 \mathrm{~min}$ after completing the experiment (i.e., Reflective stage).

The Need-Threat Scale (NTS) measures satisfaction with the four fundamental needs potentially affected by ostracism in a 12-item scale: the need to have pleasant interactions with others (belonging), the need to believe others view us as worthy (self-esteem), the need to influence our social environment (control), and the need to avoid our fear of death by making an impact on the world (meaningful existence) [51]. Lower scores reflect the "ostracism distress", e.g. a greater perceptions of threat to these fundamental needs. In this sample, the internal consistency of NTS was good across all assessment times $\left(\alpha_{\text {inclusion }}=.79\right.$; $\alpha_{\text {ostracism }}=.81 ; \alpha_{\text {reflective stage }}=.87$ ).

\section{Autonomic responses to the Cyberball game}

Patients were fitted with three $10 \mathrm{~mm} \mathrm{Ag} / \mathrm{AgCl}$ pregelled adhesive electrodes for an ECG (ADInstruments, UK) placed in an Einthoven's triangle configuration.

The ECG was sampled at $2 \mathrm{kHz}$ and online filtered with the Mains Filter. RSA values were extracted for the entire duration of the baseline-block $(120 \mathrm{~s})$, for the last $120 \mathrm{~s}$ of the condition-blocks (Inclusion and Ostracism) and at Reflective stage (120s), in line with guidelines [52].
The peak of the R-wave of the ECG was detected from each sequential heartbeat. The R-R intervals were extracted, and the artifacts were edited by integer division or summation. Editing consisted of visual detection of outlier points, typically caused by failure to detect an Rpeak (e.g., edit via division) or faulty detections of two or more peaks within a period representing the R-R interval (e.g., edit via summation). The amplitude of RSA [expressed in $\left.\ln (\mathrm{msec})^{2}\right]$, calculated as the natural logarithm of the variance of heart rate activity across the frequency band associated with spontaneous respiration, was quantified with CMetX [53, 54].

\section{Statistical analysis}

Descriptive statistics were performed to detail the sociodemographic and clinical characteristics of the sample.

\section{Cyberball experiment Manipulation checks}

Two $3 * 2$ repeated measure analyses of variance (ANOVA) with a Group (BPD vs. rMDD vs. HC) by Condition (Inclusion vs. Ostracism) design were performed, with the post-Cyberball ratings of percentages of ball tosses received and feelings of being excluded/ignored as dependent variables.

\section{Subjective responses}

A 3*3 repeated-measures ANOVA was conducted with Need-Threat Scale (NTS) scores as the dependent variable to examine how the perceived threats to fundamental needs were influenced by the clinical status (Group: $\mathrm{BPD}$ vs. rMDD vs. $\mathrm{HC}$ ) and by the experimental Condition (Inclusion vs. Ostracism vs. Reflective Stage).

\section{Autonomic responses}

Finally, a 3*4 Group (BPD vs. rMDD vs. HC) by Condition (Baseline vs. Inclusion vs. Ostracism vs. Reflective Stage) ANCOVA was used to identify whether the pattern of changes in RSA throughout the game varied among groups. Age, BMI, alcohol and tobacco consumption were considered as covariates because they could affect RSA and differed among diagnostic groups.

Simple effects analyses were used to evaluate significant main and interaction effects. All the analyses were carried out using SPSS software (IBM SPSS 25.0).

\section{Association between subjective and autonomic responses to Cyberball conditions}

Finally, we performed three linear regression analyses (enter method) to evaluate whether NTS scores predicted RSA following Inclusion, Ostracism and at the Reflective Stage, whilst controlling for confounding variables. In all the analyses, we entered the covariates 
mentioned above - age, BMI, alcohol and tobacco consumption - as well as RSA at baseline.

\section{Results \\ Sample}

The socio-demographic and clinical characteristics of the participants are shown in Table 1.

The sample consisted of 90 participants, of which $85.6 \%$ were women. This gender distribution reflects the epidemiology of BPD in clinical treatment population: although in the general population there is no $d$ ifference in the prevalence of BPD between males and females [55], in clinical settings BPD is diagnosed predominantly in females [49], likely for the greater proneness of women with BPD to seek outpatient treatment [56]. HC and patients with rMDD were matched for sex to the BPD sample, resulting in no gender differences in the three groups. In terms of age, patients with rMDD were older than both the BPD and HC groups, and, accordingly, less likely to live alone/with parents or to be students. They also had a greater BMI and reported to consume alcoholic beverages and tobacco to a lesser extent than the other groups. These differences seem to be mostly related to the age difference. As compared to the clinical groups, $\mathrm{HC}$ were more likely to have a college/university level of education and were all employed, with a greater level of global functioning.

\section{Cyberball experiment \\ Manipulation checks}

As expected, there was a significant effect of the experimental Condition on participants' ratings of both perception of percentages of ball throws received $\left(F_{1.87}=\right.$ 431.22, $\left.p<.01, \eta_{\text {partial }}^{2}=.83\right)$ and feelings of being ignored and excluded $\left(F_{1.87}=184.27, p<.01, \eta_{\text {partial }}^{2}=.68\right)$. As compared to the Inclusion condition, after Ostracism participants reported that they received a lower percentage of ball tosses (Ostracism $2.58 \pm .37<$ Inclusion $40.26 \pm 1.83$ ), and that they felt more ignored and excluded (Ostracism 4.34 $\pm .23>$ Inclusion 1.29 \pm .08 ). These results suggest that the Cyberball manipulation was successful.

Importantly, this effect held irrespective of the participants' clinical status, as indicated by the absence of any significant Group effect (percentage of throws received: $F_{2.87}=1.91, p=.15, \eta_{\text {partial }}^{2}=.04$; feeling of being ignored/excluded: $F_{2.87}=1.13, p=.33, \eta_{\text {partial }}^{2}=.03$ ) nor Group by Condition interaction (percentage of throws received: $F_{2.87}=2.06, p=.13, \eta^{2}$ partial $=.05$; feeling of being ignored/excluded: $F_{2.87}=.59, p=.55, \eta^{2}$ partial $=.01$. Thus, HC and participants with BPD and rMDD were equally cognitively aware of their inclusionary status during the game.

\section{Subjective responses to the Cyberball game}

Overall, participants reported that their fundamental needs were more threatened in the Ostracism than in the Inclusion condition $(p<.01, \mathrm{CI}=1.53,2.14)$ and were then restored at the Reflective stage, as compared with the Ostracism condition $(p<.01, \mathrm{CI}=-.51,-.11)$ (main within-subject effect of Condition; Table 2; Fig. 2A). Perception of threats to fundamental needs also varied across groups, with a tendency of BPD to report lower NTS scores (main between-subjects effect of Group without significant post hoc comparisons; Table 2). However, these main effects were better qualified by significant Group by Condition interaction (Table 2): patients with BPD reported lower satisfaction with fundamental needs than $\mathrm{HC}$ and patients with rMDD in the Inclusion condition (HC: $p<.01, \mathrm{CI}=-1.22,-.15$; rMDD: $p=.02, \mathrm{CI}=-1.13,-.06)$, but not in the Ostracism condition $(\mathrm{HC}: p=1, \mathrm{CI}=-.93, .52 ; \quad \mathrm{rMDD}: p=.62, \mathrm{CI}=-$ $1.10, .35)$ nor at Reflective stage (HC: $p=.13, \mathrm{CI}=$ 1.26,1.45; rMDD: $p=1, \mathrm{CI}=-.81, .77$ ) (effect of Group within the Group by Condition Interaction for the Inclusion condition: $\left.F_{2,87}=5.75, \eta_{\text {partial }}^{2}=.12, p<.01\right)$. Moreover, satisfaction with fundamental needs increases from the Ostracism to the Reflective stage in $\mathrm{HC}$ and patients with rMDD (HC: $p<.01, \mathrm{CI}=-.86,-.16$; rMDD: $p=.04$, $\mathrm{CI}=-.70,-.07)$, but not among patients with $\operatorname{BPD}(p=1$; $\mathrm{CI}=-.40, .30)$ (Effect of Condition within the Group by Condition interaction for the BPD group: $F_{2,86}=32.4$, $\left.\eta_{\text {partial }}^{2}=.43, p<.01\right)$ (Fig. 2A).

\section{Autonomic responses to the Cyberball game}

Overall, patients with BPD presented a lower vagal tone as compared to $\mathrm{HC}(p<.01 ; \mathrm{CI}=-2.22,-.63)$, but not to $\operatorname{rMDD}(p=.09 ; \mathrm{CI}=-1.79,0.85)$ (main between-subject effect of Group on RSA levels; Table 2; Fig. 2B). Specifically, BPD patients had lower resting RSA levels than $\mathrm{HC}(p=.02 ; \mathrm{CI}=.14,1.90)$, but did not differ from rMDD at baseline $(p=.81 ; \mathrm{CI}=-$ .57, 1.52; Effect of Group within a Group by Condition interaction for baseline RSA $F_{2.83}=4.43, \eta^{2}$ partial $=$ $.10, p=.02$; Table 2). However, patients with BPD showed a generally lower RSA than both $\mathrm{HC}$ and patients with rMDD across all the experimental conditions (vs $\mathrm{HC}$, all $p_{\mathrm{s}}<.001$; vs rMDD: Inclusion $p=$ .086; Ostracism $p=.04$, Reflective stage $p=.05$ ). Furthermore, only in the BPD group RSA levels decreased during the experiment (Effect of Condition within the Group by Condition interaction for the BPD group: $F_{3,81}=4.26, \eta_{\text {partial }}^{2}=.14, p<.01$ ), while they did not vary in HC nor rMDD patients (respectively, $F_{3,81}=1.76, \eta_{\text {partial }}^{2}=.06, p=.16$ and $F_{3,81}=1.09$, $\eta_{\text {partial }}^{2}=.04, p=.36$ ). In particular, patients with BPD exhibited a marked reduction in RSA from Baseline to Inclusion $(p=.01 ; \mathrm{CI}=.08,1.01)$; then, their $\mathrm{RSA}$ 
Table 1 Socio-demographic, clinical and psychometric characteristics

\begin{tabular}{|c|c|c|c|c|c|}
\hline & \multirow{2}{*}{$\begin{array}{l}\text { BPD } \\
n=30\end{array}$} & \multirow{2}{*}{$\begin{array}{l}\mathrm{HC} \\
\mathrm{n}=30\end{array}$} & \multirow{2}{*}{$\begin{array}{l}\text { rMMD } \\
n=30\end{array}$} & \multicolumn{2}{|l|}{ Between-groups differences } \\
\hline & & & & Main effect of factor Group* & Post-hoc comparisons \\
\hline \multicolumn{6}{|l|}{ Physiological variables } \\
\hline Age & $33.2 \pm 12.07$ & $38.9 \pm 14.65$ & $49.27 \pm 9.96$ & $F_{(2,87)}=12.98, p<.01 ; \dot{n}_{p}^{2}=.23$ & $\mathrm{rMDD}>\mathrm{BPD}, \mathrm{HC}\left(\mathrm{p}_{\mathrm{s}}<.01\right)$ \\
\hline $\operatorname{Sex}(F)$ & $27(90 \%)$ & $24(80 \%)$ & $26(86.7 \%)$ & $x^{2}(2)=1.26, p=.53$ & \\
\hline Sport & $12(40 \%)$ & $17(56.7 \%)$ & $11(36.7 \%)$ & $x^{2}(4)=4.57, p=.33$ & \\
\hline BMI & $21.77 \pm 3.75$ & $22.70 \pm 3.40$ & $26.31 \pm 6.25$ & $F_{(2,87)}=7.98, p=.01 ; \dot{n}_{p}^{2}=.15$ & $\mathrm{rMDD}>\mathrm{BPD}, \mathrm{HC}\left(\mathrm{p}_{\mathrm{s}}<.01\right)$ \\
\hline \multicolumn{6}{|l|}{ Psychotropic drugs consumption } \\
\hline Alcohol & $17(56.7 \%)$ & $21(70 \%)$ & $7(23.3 \%)$ & $x^{2}(2)=13.87, p=.01$ & \\
\hline Caffeine & $24(80 \%)$ & $26(86.7 \%)$ & $19(63.3 \%)$ & $x^{2}(2)=4.84, p=.09$ & \\
\hline Tobacco & $26(86.7 \%)$ & $8(26.7 \%)$ & $5(16.7 \%)$ & $x^{2}(2)=35.02, p<.01$ & \\
\hline \multicolumn{6}{|l|}{ Social variables } \\
\hline Education (yrs) & $11.53 \pm 2.89$ & $14.76 \pm 3.54$ & $11.23 \pm 3.35$ & $F_{(2,87)}=10.77, p<.01 ; \dot{n}_{p}^{2}=.20$ & $\mathrm{HC}>\mathrm{BPD}, \mathrm{rMDD}\left(\mathrm{p}_{\mathrm{s}}<.01\right)$ \\
\hline \multicolumn{6}{|l|}{ Family status } \\
\hline Married/living together & $7(23.3 \%)$ & $16(53.3 \%)$ & $20(66.6 \%)$ & $x^{2}(6)=16.29, p=.01$ & \\
\hline Separated/divorced & $6(20 \%)$ & $1(3.3 \%)$ & $4(13.4 \%)$ & & \\
\hline Widowed & $0(0 \%)$ & $1(3.3 \%)$ & $1(3.3 \%)$ & & \\
\hline Living alone/with parents & $17(56.7 \%)$ & $12(40 \%)$ & $5(16.7 \%)$ & & \\
\hline \multicolumn{6}{|l|}{ Occupation } \\
\hline Employed & $16(53.3 \%)$ & $17(53.4 \%)$ & $22(73.3 \%)$ & $x^{2}(6)=29.13, p=.01$ & \\
\hline Housewife & $0(0 \%)$ & $4(13.3 \%)$ & $6(20 \%)$ & & \\
\hline Students & $6(20 \%)$ & $10(33.3 \%)$ & $0(0 \%)$ & & \\
\hline Unemployed & $8(26.7 \%)$ & $0(0 \%)$ & $2(6.7 \%)$ & & \\
\hline \multicolumn{6}{|l|}{ Clinical and psychometric variables } \\
\hline \multicolumn{6}{|l|}{ DSM-5 Comorbidity } \\
\hline Adjustment disorder & $12(40 \%)$ & - & - & & \\
\hline Substance Use disorders (in full remission) & $10(33.3 \%)$ & - & - & & \\
\hline Alcohol Use disorders (in full remission) & $3(10 \%)$ & - & - & & \\
\hline Obsessive Compulsive Disorder & - & - & $1(3.3 \%)$ & & \\
\hline Eating disorders & $2(6.7 \%)$ & - & - & & \\
\hline Personality disorders & $11(36.7 \%)$ & - & $3(10 \%)$ & & \\
\hline Passive-aggressive & $2(6.7 \%)$ & - & - & & \\
\hline Paranoid & $1(3.3 \%)$ & - & - & & \\
\hline Histrionic & $2(6.7 \%)$ & - & - & & \\
\hline Narcissistic & $6(20 \%)$ & - & - & & \\
\hline Dependent & $1(3.3 \%)$ & - & - & & \\
\hline Obsessive-Compulsive & - & - & $3(10 \%)$ & & \\
\hline \multicolumn{6}{|l|}{ Medications } \\
\hline Mood stabilizers & $25(83.3 \%)$ & - & $4(13.3 \%)$ & $x^{2}(1)=28.5, p<.01$ & \\
\hline Antidepressants & $13(43.3 \%)$ & - & 30 (100\%) & $x^{2}(1)=24.7, p<.01$ & \\
\hline Antipsychotics & $22(73.3 \%)$ & - & $4(13.3 \%)$ & $X^{2}(1)=21.08, p<.01$ & \\
\hline Benzodiazepines & $21(70 \%)$ & - & $14(46.7 \%)$ & $x^{2}(1)=4.05, p=.04$ & \\
\hline Duration of illness & $15.20 \pm 12.1$ & & $11.77 \pm 8.77$ & $F_{(1.58)}=1.59, p=.21 ; n_{p}^{2}=.03$ & \\
\hline Matrix reasoning & $16.80 \pm 2.42$ & $20.10 \pm 2.94$ & $18.17 \pm 3.38$ & $F_{(2,87)}=9.52, p<.01 ; \dot{n}_{p}^{2}=.18$ & $\mathrm{HC}>\mathrm{BPD}, \mathrm{rMDD}\left(\mathrm{p}_{\mathrm{s}}<.04\right)$ \\
\hline GAF & $72.07 \pm 7.31$ & $96.6 \pm 4.76$ & $86.57 \pm 6.39$ & $F_{(2,87)}=117.11, p<.01 ; \dot{n}_{p}^{2}=.73$ & $\mathrm{HC}>\mathrm{rMDD}>\mathrm{BPD}\left(\mathrm{p}_{\mathrm{s}}<.01\right)$ \\
\hline
\end{tabular}

*F-Tests in One-way ANOVA have been performed to compare continuous variables; Chi square tests ( $\mathrm{X} 2$ ) have been performed to compare categorical variables. $\mathrm{BPD}=$ patients with Borderline Personality Disorder; $\mathrm{HC}=$ Healthy Controls; rMDD = patients with Major Depressive Disorder in remission; BMI = Body Mass Index; $\mathrm{GAF}=$ Global Assessment of Functioning 
Table 2 Effect of Experimental Condition, Group Status and Their Interactions on NTS scores and RSA levels

\begin{tabular}{|c|c|c|c|c|c|c|}
\hline Variables & BPD & $\mathrm{HC}$ & rMDD & Condition & Group & Interactions Condition X Group \\
\hline NTS scores & & & & $\begin{array}{l}\mathrm{F}_{2,86}=121.34^{\mathrm{a}} \\
\eta^{2} \text { partial }=.74 \\
p<.01\end{array}$ & $\begin{array}{l}F_{2,87}=3.41 \\
\eta_{\text {partial }}=.07 \\
p=.04\end{array}$ & $\begin{array}{l}F_{2,87}=3.24 \\
\eta_{\text {partial }}=.07 \\
p=.04\end{array}$ \\
\hline Inclusion & $4.57 \pm .15$ & $5.26 \pm .15$ & $5.16 \pm .15$ & & & \\
\hline Ostracism & $2.95 \pm .21$ & $3.15 \pm .21$ & $3.33 \pm .21$ & & & \\
\hline Reflective stage & $3.00 \pm .23$ & $3.66 \pm .23$ & $3.69 \pm .23$ & & & \\
\hline RSA levels & & & & $\begin{array}{l}\mathrm{F}_{3,81}=.29 \\
\eta_{\text {partial }}=.01 \\
p=.84\end{array}$ & $\begin{array}{l}F_{2,83}=9.87 \\
\eta_{\text {partial }}^{2}=.19 \\
p<.01\end{array}$ & $\begin{array}{l}\mathrm{F}_{3,82}=3.44 \\
\eta^{2} \text { partial }=.01 \\
p=.02\end{array}$ \\
\hline Baseline & $4.52 \pm .27$ & $5.54 \pm .22$ & $4.99 \pm .26$ & & & \\
\hline Inclusion & $3.98 \pm .27$ & $5.56 \pm .22$ & $4.94 \pm .26$ & & & \\
\hline Ostracism & $4.07 \pm .26$ & $5.61 \pm .21$ & $5.12 \pm .25$ & & & \\
\hline Reflective stage & $4.28 \pm .24$ & $5.83 \pm .20$ & $5.21 \pm .23$ & & & \\
\hline
\end{tabular}

$\mathrm{BPD}=$ patients with Borderline Personality Disorder; $\mathrm{HC}=$ Healthy Controls; rMDD = patients with Major Depressive Disorder in remission; NTS = Need Threat Scale; RSA $=$ Respiratory Sinus Arrhythmia

levels did not vary and remained low moving from the Inclusion to the Ostracism condition $(p=1, \mathrm{CI}=-$ $.51, .31)$ and from Ostracism to the Reflective stage $(p=1, \mathrm{CI}=-.62, .22)($ Fig. 2B).

\section{Association between subjective and autonomic responses to Cyberball condition}

Having found that participants with BPD, as compared with non-BPD controls, reported greater threats to their fundamental needs as well as a marked decrease in RSA after the Cyberball Inclusion condition, we next evaluated whether the subjective perception of threat in the overall sample was associated with a breakdown of vagal control at the physiological level. NTS scores predicted RSA levels only in the Inclusion condition $(b=$ $.22, p=.04)$, but not after Ostracism $(b=.08, p=.48)$ nor at the Reflective stage $(b=.04, p=.69)$. This held true even after controlling, as above, for age, BMI, alcohol and tobacco consumption and also for the baseline levels of RSA (Inclusion: $b=.11, p=.05$; Ostracism: $b=-.05$, $p=.32$; Reflective stage: $b=.05, p=.41)$, indicating that higher perception of threats to fundamental needs after

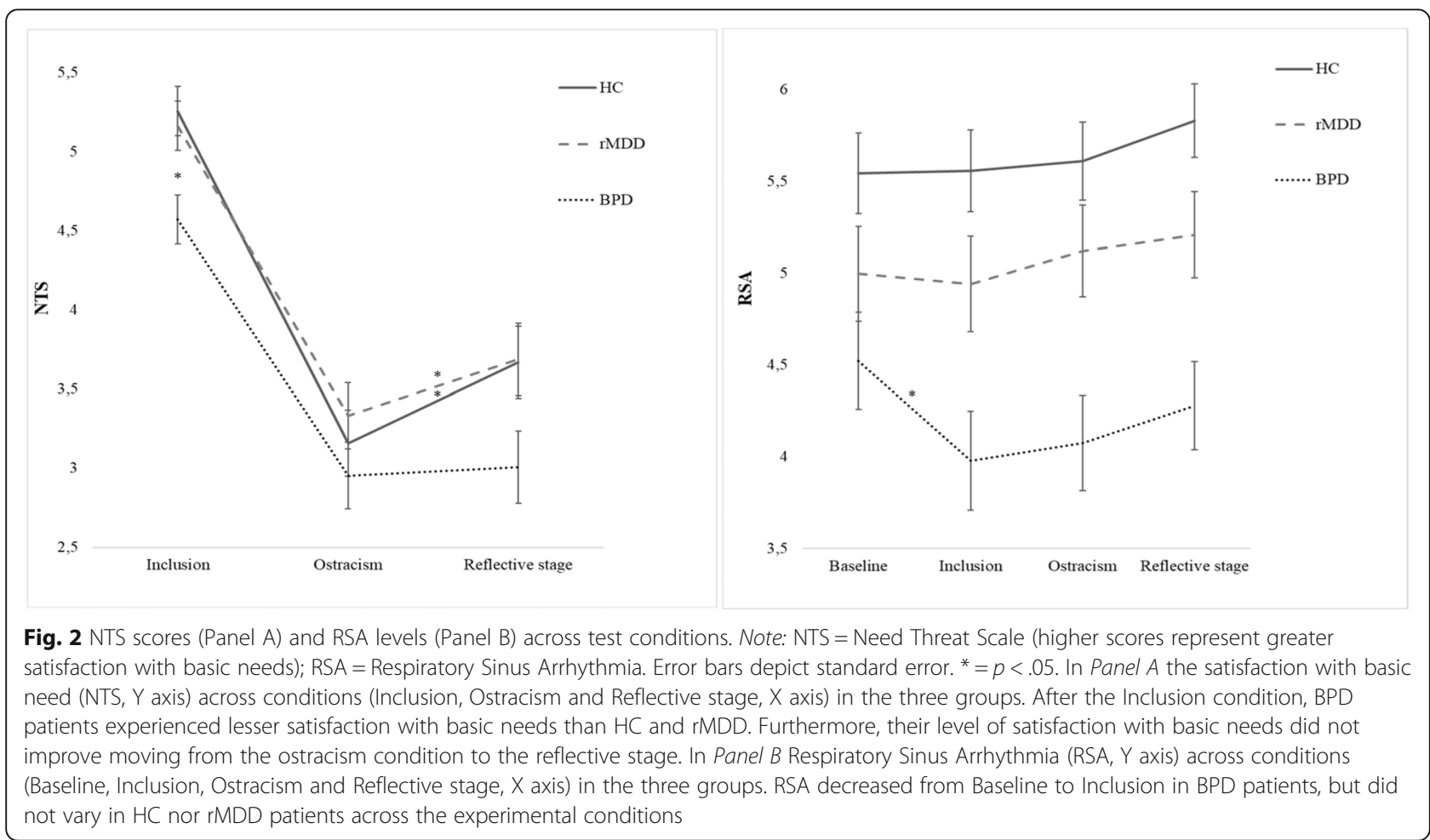


being included by others parallels a less efficient vagal control during including social interactions. Notably, we did not control this association for multiple comparisons.

\section{Discussion}

The present study investigated whether BPD's biased perception of social interactions is associated with reduced physiological regulation, as indexed by impaired vagal control, in response to experimental conditions of social Inclusion and Ostracism. Three main findings emerged.

Firstly, during the Cyberball task, individuals with BPD subjectively reacted to inclusion with a higher perception of threat to fundamental needs than healthy and clinical controls. Furthermore, while in non-BPD controls the fundamental needs were restored at the Reflective stage, patients with BPD did not show such recovery from ostracism. Secondly, patients with BPD presented lower resting RSA than $\mathrm{HC}$, indicating stable difficulties in social predisposition. Moreover, only in patients with BPD, RSA further decreased in the inclusion condition and remained low during Ostracism and the Reflective stage. Finally, greater subjective perception of threats to fundamental needs in the Inclusion condition was associated with decreased RSA after being included, indicating that, during the Cyberball experiment, subjective and physiological measures of perceived threats after being included paralleled each other.

At the subjective level, after being ostracized, as expected, all participants reported being threatened in their fundamental needs [6]. However, only in the Inclusion condition patients with BPD reported a weaker sense of belongingness than did $\mathrm{HC}$ and patients with rMDD. This indicates that patients with BPD do not over-react to actual rejection, which is subjectively threatening for everybody; instead, they emotionally react to including interpersonal situations as they were threatening. Although patients with BPD appeared cognitively aware of the different degrees of threat conveyed by Inclusion and Ostracism and correctly estimated the percentage of ball tosses received during each condition, they subjectively perceived a higher level of danger in the including and accepting interaction than non-BPD participants. This is in line with previous Cyberball studies showing that patients with BPD during the Inclusion condition experienced a greater sense of exclusion and a lesser sense of inclusion and belonging [8-11, 57] and reported lower feelings of social connection and greater threats to their social needs than controls even when over-included by others [11, 12]. Thus, patients with BPD show a biased subjective experience of social inclusion during Cyberball $[8,57]$.
Furthermore, in line with the Temporal NeedThreat Model of ostracism [51], in this study, threatened needs quickly recovered a few minutes after Ostracism among both $\mathrm{HC}$ and rMDD. While the detection of ostracism immediately generates negative emotions, this in turn quickly motivates individuals to regulate their initial social pain in order to access more positive emotions and restore functional relations with others after Ostracism is over. Conversely, in this study patients with BPD did not recover from Ostracism; rather, they kept reporting feeling threatened in their need to belong. The ability to recover faster and in more functional ways from social exclusion has been found in individuals with higher psychological flexibility levels. By contrast, a delayed emotional recovery suggests difficulties in access to, and use of, a wider range of emotion regulation strategies to cope with ostracism experiences [58, 59]. For instance, socially anxious individuals exhibit a slow recovery from the negative feelings induced by ostracism [60].

This study also demonstrated that these explicit, subjective findings parallel a corresponding pattern of change in ANS reactivity at the implicit, physiological level. BPD patients exhibited a lower RSA at baseline than HC. Moreover, they also uniquely showed a further decrease in RSA after the Cyberball Inclusion condition - when they also reported, at the subjective level, to be threatened (more than non-BPD controls) in their need to belong.

Concerning baseline RSA, the present findings confirm that patients with BPD show lower vagal control at rest than $\mathrm{HC}[17-21]$. This indicates that even in the absence of interpersonal challenges (i.e., even before the Cyberball experiment), the BPD group exhibits a physiological state of preparedness for defensive rather than prosocial behaviors. Notably, the finding of low RSA at rest in clinical populations, as compared to $\mathrm{HC}$, is not limited to $\mathrm{BPD}$ but also characterizes patients with anxiety disorders, conduct disorders, autism spectrum disorders, depression and schizophrenia (see for a review [61]) and, in this study, also patients with MDD in remission. This is not surprising given that patients with diverse psychiatric disorders exhibit various degrees of social dysfunction that are likely to be paralleled, at the ANS level, by the inhibition of the social engagement system when the vagal brake is removed. This study extends these findings by indicating that even after clinical remission patients with MDD maintain a state of physiological arousal predisposing to defensive rather than prosocial behaviors; consistently, they also showed lower psychosocial functioning than $\mathrm{HC}$, as indexed by lower GAF 
scores, possibly as a "scar effect" of previous episodes. Thus, low RSA at rest, rather than being disorder-specific, could represent a marker of the difficulties in social behaviors shared by several psychiatric disorders.

However, among $\mathrm{HC}$ and patients with rMDD, RSA levels did not change from baseline across the three Cyberball experimental conditions. This indicates that they correctly appraised, at the physiological level, that the task conveyed only minimal interpersonal stress (Cyberball lasted about two minutes and involved two unknown avatars online), but not greater threatening risks. Thus, the experimental Cyberball conditions employed in this study ultimately favored, among HC and patients with rMDD, the maintenance of their vagal regulation on the heart during and after the experiment. Therefore, while at the subjective level both $\mathrm{HC}$ and patients with rMDD accurately perceived the Ostracism condition as threatening their need to belong, they maintained their capacity to regulate the vagal control and then quickly recovered from their negative affective states at the Reflective stage. On the contrary, patients with BPD experienced a further drop in RSA after the benign experimental condition of Inclusion. This vagal withdrawal then persisted even at the reflective stage. Thus, patients with BPD are not only biased to subjectively perceive rejection even in including contexts, or when ostracism is over: they also implicitly appraise, at the physiological level, such benign conditions as signaling threats in the environment. This altered neuroception [13] of favorable social environments, in turn, leads BPD patients to regulate their ANS to a state that would support fight and flight responses but impedes social flexibility and prosociality even after including interpersonal exchanges or when social interactions are over. These findings are in keeping with other studies investigating the potential neurophysiological bases of BPD biased perception of rejection. For instance, during the Cyberball Inclusion condition, patients with BPD show an enhanced P3b event-related potential, which usually signals social rejection [12, 62] and hyper-activate the "social pain" neural circuitry (i.e., the dorsal anterior cingulate cortex and the dorsomedial prefrontal cortex) [10]. These data suggest that patients with BPD process objectively positive social interactions by activating physiological and neural responses that signal rejection and threat.

Finally, in this study, the subjective appraisal of threats to one's need to belong after the Inclusion condition (NTS scores) directly correlated with the physiological appraisal of the Inclusion condition as unsafe (decreased RSA ratings after Inclusion), but not in any other stage of the Cyberball task. This indicates that the tendency to subjectively perceive including interpersonal interactions as if they were excluding is underlined by a corresponding altered physiological appraisal of such safe context as if it was unsafe and risky. Such altered appraisal inevitably leads to the inappropriate activation of the ANS defensive systems in an environment that is actually safe and inhibits the prosocial responses fostered by the myelinated vagal regulation, which though would be required and adaptive in safe contexts [13].

Overall, these results point out to a "lowered ostracism detection threshold" in BPD: when the threshold for detecting signals of ostracism in the environment is set too low, the ostracism detection system registers a high proportion of false positives, interpreting benign (or even mildly favorable) interpersonal events as potential threats to acceptance [63]. Such interpretation is supported by converging lines of evidence indicating that patients with BPD systematically underestimate positive feedback from others. For instance, they show lesser expectations of being socially accepted than controls and cannot adjust these expectations even after receiving actual positive feedback [64]. Furthermore, in behavioural economics games, BPD under-notice others' fair behaviour toward them and react to that as if it was unfair by punishing them [65]. Moreover, after experiencing actual social acceptance, they behave less cooperatively toward others [64]. Finally, individuals with BPD respond with less positive emotions than controls to others' friendly behaviour [66], and under-notice trust in others [67-69].

These findings are also consistent with clinical observations that patients with BPD do not seem to benefit from benign, "fair" and accepting attitudes of others toward them to regulate their emotional states, nor from neutral interpersonal conditions where interpersonal rejection, although experienced in the past, is no longer occurring. According to object-relations theory [70, 71], this response pattern may reflect the patient's unconscious idealized need of finding a perfectly "accepting" relationship with others. However, this intense need is unlikely to be fulfilled in reality, since human interactions may also exhibit transient difficulties or ruptures that are usually overcome by repairing trust and maintaining reciprocity. For patients with BPD, though, such less-than-perfect interpersonal interactions may not be enough to fulfill their unconscious idealized need for interpersonal belonging. Thus, in the desperate attempt to protect this unconscious hope of a "perfect" relationship, individuals with BPD need to project one's negative affect into the others; this makes them perceive including social interactions as if they were unfair and excluding. This threatens the possibility to feel safe and connected during "real" interpersonal exchanges.

Such dynamics could have significant implications for treatment. Patients with BPD could feel easily threatened, hurt and ignored even in the context of 
therapeutic relationships, and may find it difficult to appraise them as trustworthy, regardless of the objectively cooperative stance of the therapist. This may affect the therapeutic alliance and possibly evoke negative countertransference reactions in the clinicians, such as feelings of frustration, inadequacy, and hopelessness. It is hence important, for the clinician, to recognize that these feelings in fact correspond to some aspects of their patients' inner experience that they cannot tolerate. By maintaining this empathic focus, the therapist can then explore with the patients their perception to be threatened during treatment and help them to appreciate that, although the therapeutic relationship cannot provide a perfect or magical solution to their problems, it can nonetheless represent something of value to them. In the same vein, the clinicians may encourage BPD patients to recognize positive aspects in their real-life interpersonal relationships by clarifying the defensive distortion of benign interpersonal encounters as threatening. In turn, this will favor the development of more gratifying and satisfactory interpersonal relationships [72].

The results of this study should be interpreted in light of some limitations.

First, our patients with BPD and rMDD exhibited some socio-demographical differences, above all age. This reflects the epidemiological distribution of BPD and MDD. While BPD has an onset in adolescence or early adulthood, and most patients experience symptomatic remission in a few decades [73], MDD can develop at any age, with a median age at onset at 30-40 years [74].

Moreover, we could not rule out the role of pharmacotherapy on RSA levels, since both the clinical groups kept their usual medication regimen, in compliance with the Local Ethical Authority requirements and good clinical practice. Nonetheless, in this study, patients with $(N=43)$ and without $(N=17)$ antidepressants did not differ in baseline RSA $\left(F_{1.51}=\right.$ $\left..38, p=.54, \eta 2_{\text {partial }}=.01\right)$, regardless of their clinical group status. Moreover, in our analyses, we controlled for other physiological variables that have previously been demonstrated to affect RSA (i.e., age, BMI, alcohol and tobacco consumption) [75-78].

Furthermore, while in the present study healthy and clinical controls subjectively perceived the ostracism condition as potentially threatening (thereby confirming the widely-replicated validity of the Cyberball experimental manipulation), at the physiological level they did not exhibit a parallel withdrawal in RSA. This is likely due to the successful recruitment of self-regulatory abilities in $\mathrm{HC}$ and in patients with $\mathrm{rMDD}$, which favored the appraisal, at the physiological level, of the Cyberball ostracism condition as a minimal and transient interpersonal stress, and therefore the maintenance of vagal control. This was not the case for patients with BPD, who are known to react with increasing distress to any situation where rejection is a possibility (in the present study, to the Cyberball social inclusion condition) because of their self-regulation difficulties [79, 80]. A subsequent vagal suppression did not occur from inclusion to ostracism, among patients with BPD, because it was already withdrawn from baseline to inclusion, and RSA reactivity scores could be susceptible to a floor effect of functional adaptations [81].

Finally, in our study, we interpreted RSA in the Polyvagal Theory framework, which posits that RSA suppression is associated with the neurophysiological appraisal of the environment as dangerous, thus leading to defensive, rather than pro-social behaviors. However, contradictory findings have been reported regarding RSA changes in response to varying environmental cues [82] and some researchers suggested that the evolution of the parasympathetic ANS has a greater anatomical and physiological complexity than what was proposed by the Polyvagal Theory $[16,83]$. Therefore, the specificity of RSA as a physiological marker of BPD patients' biased perception of social participation needs to be confirmed by further research.

\section{Conclusions}

The results of this study indicate that patients with BPD perceive (at the subjective level) threats to their need to belong during accepting social encounters, as well as when the experience of ostracism is no longer present. They also appraise (at the implicit, physiological level) such circumstances as threatening and dangerous, thereby showing an autonomic response characterized by increased physiological arousal and proneness to defensive reactions and breakdown in prosocial behavior. These findings support the view that patients with BPD appraise and react, both subjectively and physiologically, to positive social contexts as if they were unsafe and rejecting. This prevents them from appreciating and reciprocating objectively inclusive, "fair" social exchanges. Thus, individuals with BPD may benefit from interventions that help them to accurately appraise positive cues in their social and interpersonal interactions.

\footnotetext{
Abbreviations

ANOVA: analyses of variance; ANS: Autonomic Nervous System; BMI: Body Mass Index; BPD: Borderline Personality Disorder; ECG: Electrocardiogram; GAF: Global Assessment of Functioning; HAM-A: Hamilton Anxiety Rating Scale; HAM-D: Hamilton Rating Scale for Depression; HC: Healthy Controls; NTS: Need-Threat Scale; rMDD: remitted Major Depressive Disorder; RSA: Respiratory Sinus Arrhythmia; SCID-5-PD: Structured Clinical Interview for DSM-5 Personality Disorders; SCID5-CV: Structured Clinical Interview for DSM5 disorders, Clinician Version
}

Acknowledgements

Not applicable. 


\section{Authors' contributions}

Authors MLG, MA, PR, EP, BM, CDP, and VG designed the study. Authors $M L G, M A, S M, V L, P R ; E P$ and $C D P$ managed the literature searches. Authors MLG, SM and VL recruited the participants. Authors MLG, MA, SM and PO undertook the statistical analysis. Authors MLG, MA and CDP wrote the first draft of the manuscript. MLG, MA, SM, VL, CDP, PR, EP, PO, CM and VG interpreted the results. All authors contributed to and have approved the final manuscript.

\section{Funding}

This work was supported by Paola Chiesi and by a PRIN grant on Perception, Performativity and the Cognitive Sciences to VG.

\section{Availability of data and materials}

The dataset analyzed during the current study is available from the corresponding author on reasonable request.

\section{Declarations}

\section{Ethics approval and consent to participate}

Participants gave written informed consent to participation and, after completion of the experiment, were extensively debriefed and given detailed information about the study and its purposes, with the opportunity to have their data deleted should they wish so. Participants were not reimbursed for their participation. The Local Ethical Authority (Comitato Etico Unico per Parma, protocol \#6266 01/29/2016) approved the study protocol. All procedures contributing to this work comply with the relevant national and international committees' ethical standards on human experimentation and with the Helsinki Declaration of 1972, as revised in 2013.

\section{Consent for publication}

Not applicable.

\section{Competing interests}

The authors declare that they have no competing interests.

\section{Author details}

${ }^{1}$ Department of Mental Health, AUSL of Parma, Parma, Italy. ${ }^{2}$ Department of Medicine and Surgery, University of Parma, Parma, Italy. ${ }^{3}$ Department of Psychology, University of Milano-Bicocca, Milan, Italy.

\section{Received: 15 August 2021 Accepted: 20 October 2021} Published online: 18 November 2021

\section{References}

1. Lenzenweger MF. Current status of the scientific study of the personality disorders: an overview of epidemiological, longitudinal, experimental psychopathology, and neurobehavioral perspectives. J Am Psychoanal Assoc. 2010;58(4):741-78 https://doi.org/10.1177/0003065110386111.

2. Gunderson JG, Stout RL, McGlashan TH, Shea MT, Morey LC, Grilo CM, et al. Ten-year course of borderline personality disorder: psychopathology and function from the collaborative longitudinal personality disorders study. Arch Gen Psychiatry. 2011;68(8):827-37. https://doi:10.1001/archgenpsychia try.2011.37.

3. Gunderson JG. Revising the borderline diagnosis for DSM-V: an alternative proposal. J Personal Disord. 2010;24(6):694-708. https://doi.org/10.1521/ pedi.2010.24.6.694.

4. Clarkin JF, Yeomans FE, Kernberg OF. Psychotherapy for borderline personality disorder: focusing on object relations. Washington, DC: American Psychiatric Press; 2006.

5. Poggi A, Richetin J, Preti E. Trust and rejection sensitivity in personality disorders. Curr Psychiatry Rep. 2019;21(8):1-9 https://doi.org/10.1007/s1192 0-019-1059-3.

6. Williams KD, Jarvis B. Cyberball: a program for use in research on interpersonal ostracism and acceptance. Behav Res Methods. 2006;38(1): 174-80. https://doi.org/10.3758/BF03192765.

7. Hartgerink $\mathrm{CH}$, Van Beest I, Wicherts JM, Williams KD. The ordinal effects of ostracism: a meta-analysis of 120 Cyberball studies. PLoS One. 2015;10(5): e0127002. https://doi.org/10.1371/journal.pone.0127002.

8. Staebler K, Renneberg B, Stopsack M, Fiedler P, Weiler M, Roepke S. Facial emotional expression in reaction to social exclusion in borderline personality disorder. Psychol Med. 2011;41(9):1929-38. https://doi:10.1017/ S0033291711000080

9. Renneberg B, Herm K, Hahn A, Staebler K, Lammers CH, Roepke S. Perception of social participation in borderline personality disorder. Clin Psychol Psychother. 2012;19(6):473-80. https://doi.org/10.1002/cpp.772.

10. Domsalla M, Koppe G, Niedtfeld I, Vollstädt-Klein S, Schmahl C, Bohus M, et al. Cerebral processing of social rejection in patients with borderline personality disorder. Soc Cogn Affect Neurosci. 2013;9(11):1789-97. https:// doi.org/10.1093/scan/nst176.

11. De Panfilis C, Riva P, Preti E, Cabrino C, Marchesi C. When social inclusion is not enough: implicit expectations of extreme inclusion in borderline personality disorder. Pers Disord Theory Res Treat. 2015;6(4):301. https://doi. org/10.1037/per0000132-9.

12. Weinbrecht A, Niedeggen M, Roepke S, Renneberg B. Feeling excluded no matter what? Bias in the processing of social participation in borderline personality disorder. Neurolmage: Clin. 2018;19:343-50 https://doi.org/10.1 016/j.nicl.2018.04.031.

13. Porges SW. The polyvagal perspective. Biol Psychol. 2007;74(2):116-43. https://doi.org/10.1016/j.biopsycho.2006.06.009.

14. Berntson GG, Cacioppo JT, Quigley KS. Respiratory sinus arrhythmia: autonomic origins, physiological mechanisms, and psychophysiological implications. Psychophysiology. 1993;30(2):183-96. https://doi.org/10.1111/ j.1469-8986.1993.tb01731.x.

15. Porges SW. Orienting in a defensive world: mammalian modifications of our evolutionary heritage. A polyvagal theory. Psychophysiology. 1995;32(4): 301-18. https://doi.org/10.1111/j.1469-8986.1995.tb01213.x.

16. Grossman P, Taylor EW. Toward understanding respiratory sinus arrhythmia: relations to cardiac vagal tone, evolution and biobehavioral functions. Biol Psychol. 2007;74(2):263-85. https://doi.org/10.1016/j. biopsycho.2005.11.014.

17. Kuo JR, Linehan MM. Disentangling emotion processes in borderline personality disorder: physiological and self-reported assessment of biological vulnerability, baseline intensity, and reactivity to emotionally evocative stimuli. J Abnorm Psychol. 2009;118(3):531. https://doi.org/10.103 7/a0016392-44

18. Weinberg A, Klonsky ED, Hajcak G. Autonomic impairment in borderline personality disorder: a laboratory investigation. Brain Cogn. 2009;71(3):27986. https://doi.org/10.1016/j.bandc.2009.07.014.

19. Kuo JR, Fitzpatrick S, Metcalfe RK, McMain S. A multi-method laboratory investigation of emotional reactivity and emotion regulation abilities in borderline personality disorder. J Behav Ther Exp Psychiatry. 2016;50:52-60 https://doi.org/10.1016/j.jbtep.2015.05.002.

20. Koenig J, Kemp AH, Feeling NR, Thayer JF, Kaess M. Resting state vagal tone in borderline personality disorder: a meta-analysis. Prog NeuroPsychopharmacol Biol Psychiatry. 2016;64:18-26 https://doi.org/10.1016/j. pnpbp.2015.07.002.

21. Bortolla R, Roder E, Ramella P, Fossati A, Maffei C. Emotional responsiveness in borderline personality disorder: the role of basal hyperarousal and selfreported emotional regulation. J Nerv Ment Dis. 2019;207(3):175-83. https:// doi.org/10.1097/NMD.0000000000000939.

22. Thomson ND, Beauchaine TP. Respiratory sinus arrhythmia mediates links between borderline personality disorder symptoms and both aggressive and violent behavior. J Personal Disord. 2019;33(4):544-59 https://doi.org/1 0.1521/pedi_2018_32_358.

23. Austin MA, Riniolo TC, Porges SW. Borderline personality disorder and emotion regulation: insights from the polyvagal theory. Brain Cogn. 2007; 65(1):69-76. https://doi.org/10.1016/j.bandc.2006.05.007.

24. Beeney JE, Levy KN, Gatzke-Kopp LM, Hallquist MN. EEG asymmetry in borderline personality disorder and depression following rejection. Pers Disord: Theory Res Treat. 2014;5(2):178. https://doi.org/10.1037/per000003285.

25. Jobst A, Sabass L, Palagyi A, Bauriedl-Schmidt C, Mauer MC, Sarubin N, et al. Effects of social exclusion on emotions and oxytocin and cortisol levels in patients with chronic depression. J Psychiatr Res. 2015;60:170-7 https://doi. org/10.1016/.jpsychires.2014.11.001.

26. Hsu DT, Sanford BJ, Meyers KK, Love TM, Hazlett KE, Walker SJ, et al. It still hurts: altered endogenous opioid activity in the brain during social rejection and acceptance in major depressive disorder. Mol Psychiatry. 2015;20(2): 193-200 https://doi.org/10.1038/mp.2014.185.

27. Ernst M, Mohr HM, Schött M, Rickmeyer C, Fischmann T, Leuzinger-Bohleber $M$, et al. The effects of social exclusion on response inhibition in borderline 
personality disorder and major depression. Psychiatry Res. 2018;262:333-9 https://doi.org/10.1016/j.psychres.2017.03.034.

28. Groschwitz RC, Plener PL, Groen G, Bonenberger M, Abler B. Differential neural processing of social exclusion in adolescents with non-suicidal selfinjury: an fMRI study. Psychiatry Res Neuroimaging. 2016;255:43-9 https:// doi.org/10.1016/j.pscychresns.2016.08.001.

29. Reinhard MA, Dewald-Kaufmann J, Wuestenberg T, Musil R, Barton BB, Jobst $A$, et al. The vicious circle of social exclusion and psychopathology: a systematic review of experimental ostracism research in psychiatric disorders. Eur Arch Psychiatry Clin Neurosci. 2020;270(5):521-32 https://doi. org/10.1007/s00406-019-01074-1.

30. Zhang Q, Li X, Wang K, Zhou X, Dong Y, Zhang L, et al. Dull to social acceptance rather than sensitivity to social ostracism in interpersonal interaction for depression: behavioral and electrophysiological evidence from Cyberball tasks. Front Hum Neurosci. 2017;11:162 https://doi.org/10.33 89/fnhum.2017.00162.

31. Malejko K, Neff D, Brown R, Plener PL, Bonenberger M, Abler B, et al. Neural correlates of social inclusion in borderline personality disorder. Front Psychiatry. 2018;9:653 https://doi.org/10.3389/fpsyt.2018.00653.

32. Olié E, Jollant F, Deverdun J, de Champfleur NM, Cyprien F, Le Bars E, et al. The experience of social exclusion in women with a history of suicidal acts: a neuroimaging study. Sci Rep. 2017;7(1):1-8 https://doi.org/10.1038/s41598017-00211-x

33. Carvalho Fernando S, Beblo T, Schlosser N, Terfehr K, Otte C, Löwe B, et al. The impact of self-reported childhood trauma on emotion regulation in borderline personality disorder and major depression. J Trauma Dissociatio. 2014;15(4):384-401. https://doi.org/10.1080/15299732.2013.863262.

34. Bylsma LM, Salomon K, Taylor-Clift A, Morris BH, Rottenberg J. RSA reactivity in current and remitted major depressive disorder. Psychosom Med. 2014; 76(1):66. https://doi.org/10.1097/PSY.0000000000000019-73.

35. Judd LL, Akiskal HS, Maser JD, Zeller PJ, Endicott J, Coryell W, et al. A prospective 12-year study of subsyndromal and syndromal depressive symptoms in unipolar major depressive disorders. Arch Gen Psychiatry. 1998;55(8):694-700. https://doi.org/10.1001/archpsyc.55.8.694.

36. Kendler KS, Gatz M, Gardner CO, Pedersen NL. Personality and major depression: a Swedish longitudinal, population-based twin study. Arch Gen Psychiatry. 2006;63(10):1113-20. https://doi.org/10.1001/archpsyc.63.10.1113.

37. Shea MT, Leon AC, Mueller TI, Solomon DA, Warshaw MG, Keller MB. Does major depression result in lasting personality change? Am J Psychiatr. 1996; 153(11):1404-10. https://doi.org/10.1176/ajp.153.11.1404.

38. Hamilton JL, Alloy LB. Atypical reactivity of heart rate variability to stress and depression across development: systematic review of the literature and directions for future research. Clin Psychol Rev. 2016;50:67-79 https://doi. org/10.1016/j.cpr.2016.09.003

39. Gunderson JG, Morey LC, Stout RL, Skodol AE, Shea MT, McGlashan TH, et al. Major depressive disorder and borderline personality disorder revisited: longitudinal interactions. J Clin Psychiatry. 2004;65(8):1049-56. https://doi. org/10.4088/JCP.v65n0804.

40. Goodman M, New AS, Triebwasser J, Collins KA, Siever L. Phenotype, endophenotype, and genotype comparisons between borderline personality disorder and major depressive disorder. J Personal Disord. 2010; 24(1):38-59 https://doi.org/10.1521/pedi.2010.24.1.38.

41. First MB, Williams JB, Karg RS, Spitzer RL. Structured clinical interview for DSM-5 disorders: SCID-5-CV clinician version. Arlington, VA: American Psychiatric Association Press; 2016.

42. First MB, Williams JB, Benjamin LS, Spitzer RL. Structured clinical interview for DSM- $5^{\circledR}$ personality disorders (SCID-5-PD): with the structured clinical interview for DSM-5 ${ }^{\oplus}$ screening personality questionnaire (SCID-5-SPQ). Arlington, VA: American Psychiatric Association Press; 2016.

43. Hamilton M. A rating scale for depression. J Neurol Neurosurg Psychiatry. 1960;23(1):56. https://doi.org/10.1136/jnnp.23.1.56-62.

44. Hamilton M. The assessment of anxiety states by rating. $\mathrm{Br} J$ Health Psychol. 1959;32(1):50-5 https://doi.org/10.1111/j.2044-8341.1959.tb00467.x.

45. Wechsler D. Wechsler intelligence scale for children. 5th ed. San Antonio, TX: NCS Pearson; 2014

46. Williams KD, Cheung CK, Choi W. Cyberostracism: effects of being ignored over the internet. J Pers Soc Psychol. 2000;79(5):748. https://doi.org/10.1037/ 0022-3514.79.5.748-62.

47. Faul F, Erdfelder E, Lang AG, Buchner A. G* power 3: a flexible statistical power analysis program for the social, behavioral, and biomedical sciences. Behav Res Methods. 2007;39(2):175-91 https://doi.org/10.3758/BF03193146.
48. Seidl E, Padberg F, Bauriedl-Schmidt C, Albert A, Daltrozzo T, Hall J, et al. Response to ostracism in patients with chronic depression, episodic depression and borderline personality disorder a study using Cyberball. J Affect Disord. 2020;260:254-62 https://doi.org/10.1016/j.jad.2019.09.021.

49. American Psychiatric Association. Diagnostic and statistical manual of mental disorders. 5th ed. Arlington, VA: American Psychiatric Association Press; 2013.

50. Eisenberger $\mathrm{NI}$, Lieberman MD, Williams KD. Does rejection hurt? An fMRI study of social exclusion. Science. 2003;302(5643):290-2. https://doi.org/1 $0.1126 /$ science. 1089134.

51. Williams KD. Ostracism: a temporal need-threat model. Adv Exp Soc Psychol. 2009;41:275-314 https://doi.org/10.1016/S0065-2601(08)00406-1.

52. Berntson GG, Thomas Bigger Jr J, Eckberg DL, Grossman P, Kaufmann PG, Malik M. Heart rate variability: origins, methods, and interpretive caveats. Psychophysiology. 1997;34(6):623-48 https://doi.org/10.1111/j.1469-8986.1 997.tb02140.x

53. Allen JJ, Chambers AS, Towers DN. The many metrics of cardiac chronotropy: a pragmatic primer and a brief comparison of metrics. Biol Psychol. 2007;74(2):243-62. https://doi.org/10.1016/j.biopsycho.2006.08.005.

54. Ardizzi M, Sestito M, Martini F, Umiltà MA, Ravera R, Gallese V. When age matters: differences in facial mimicry and autonomic responses to peers' emotions in teenagers and adults. PLoS One. 2014;9(10):e110763. https:// doi.org/10.1371/journal.pone.0110763.

55. Busch AJ, Balsis S, Morey LC, Oltmanns TF. Gender differences in borderline personality disorder features in an epidemiological sample of adults age 55-64: self versus informant report. J Personal Disord. 2016;30(3):419-32 https://doi.org/10.1521/pedi_2015_29_202.

56. Skodol AE, Bender DS. Why are women diagnosed borderline more than men? Psychiatr Q. 2003;74(4):349-60 https://doi.org/10.1023/A:102608741 0516

57. Wrege JS, Ruocco AC, Euler S, Preller KH, Busmann M, Meya L. Negative affect moderates the effect of social rejection on frontal and anterior cingulate cortex activation in borderline personality disorder. Cogn Affect Behav Neurosci. 2019;19(5):1-13. https://doi.org/10.3758/s13415-01 9-00716-0.

58. Waldeck D, Tyndall I, Riva P, Chmiel N. How do we cope with ostracism? Psychological flexibility moderates the relationship between everyday ostracism experiences and psychological distress. J Contextual Behav Sci. 2017;6(4):425-32. https://doi.org/10.1016/j.jcbs.2017.09.001.

59. Riva P, Eck J. Social exclusion. Berlin: Springer; 2016. https://doi.org/10.1007/ 978-3-319-33033-4.

60. Zadro L, Boland C, Richardson R. How long does it last? The persistence of the effects of ostracism in the socially anxious. J Exp Soc Psychol. 2006;42(5): 692-7. https://doi.org/10.1016/j.jesp.2005.10.007.

61. Beauchaine TP. Respiratory sinus arrhythmia: a transdiagnostic biomarker of emotion dysregulation and psychopathology. Curr Opin Psychol. 2015;3:437 https://doi.org/10.1016/j.copsyc.2015.01.017.

62. Gutz L, Renneberg B, Roepke S, Niedeggen M. Neural processing of social participation in borderline personality disorder and social anxiety disorder. J Abnorm Psychol. 2015;124(2):421. https://doi.org/10.1037/a0038614-31.

63. Leary MR, Guadagno J. The sociometer, self-esteem, and the regulation of interpersonal behavior. In Baumeister RF, Vohs K. Handbook of selfregulation (2nd ed.) New York: Guilford; 2011.

64. Liebke L, Koppe G, Bungert M, Thome J, Hauschild S, Defiebre N. Difficulties with being socially accepted: an experimental study in borderline personality disorder. J Abnorm Psychol. 2018;127(7):670-82. https://doi.org/1 $0.1037 / a b n 0000373$.

65. De Panfilis C, Schito G, Generali I, Gozzi LA, Ossola P, Marchesi C, et al. Emotions at the border: increased punishment behavior during fair interpersonal exchanges in borderline personality disorder. J Abnorm Psychol. 2019;128(2):162. https://doi.org/10.1037/abn0000404-72.

66. Sadikaj G, Moskowitz DS, Zuroff DC. Attachment-related affective dynamics: differential reactivity to others' interpersonal behavior. J Pers Soc Psychol. 2011;100(5):905. https://doi.org/10.1037/a0022875-17.

67. Unoka Z, Seres I, Áspán N, Bódi N, Kéri S. Trust game reveals restricted interpersonal transactions in patients with borderline personality disorder. J Personal Disord. 2009;23(4):399-409. https://doi.org/10.1521/ pedi.2009.23.4.399.

68. Fertuck EA, Grinband J, Stanley B. Facial trust appraisal negatively biased in borderline personality disorder. Psychiatry Res. 2013;207(3):195-202. https:// doi.org/10.1016/j.psychres.2013.01.004. 
69. Richetin J, Poggi A, Ricciardelli P, Fertuck EA, Preti E. The emotional components of rejection sensitivity as a mediator between borderline personality disorder and biased appraisal of trust in faces. Clin Neuropsychiatry. 2018;15(4):200-5. https://doi.org/10.1521/pedi_2013_27_ 096.

70. Kernberg OF. Severe personality disorders. New Haven: Yale University Press; 1984.

71. Yeomans FE, Clarkin JF, Kernberg OF. Transference-focused psychotherapy for borderline personality disorder. A clinical guide. Washington, DC: American Psychiatric Publishing; 2015. https://doi.org/10.1176/appi.books. 9781615371006.

72. Hersh RG, Caligor E, Yeomans FE. Fundamentals of transference-focused psychotherapy: applications in psychiatric and medical settings. Berlin: Springer; 2017. https://doi.org/10.1007/978-3-319-44091-0.

73. Cohen P, Crawford TN, Johnson JG, Kasen S. The children in the community study of developmental course of personality disorder. J Personal Disord. 2005:19(5):466-86. https://doi.org/10.1521/pedi.2005.19.5.466.

74. Kessler RC, Berglund P, Demler O, Jin R, Koretz D, Merikangas KR, et al. The epidemiology of major depressive disorder: results from the National Comorbidity Survey Replication (NCS-R). JAMA. 2003;289(23):3095-105. https://doi.org/10.1001/jama.289.23.3095.

75. Masi CM, Hawkley LC, Rickett EM, Cacioppo JT. Respiratory sinus arrhythmia and diseases of aging: obesity, diabetes mellitus, and hypertension. Biol Psychol. 2007;74(2):212-223.75 https://doi.org/10.1016/j.biopsycho.2006.07. 006.

76. Licht CM, de Geus EJ, Zitman FG, Hoogendijk WJ, van Dyck R, Penninx BW. Association between major depressive disorder and heart rate variability in the Netherlands study of depression and anxiety (NESDA). Arch Gen Psychiatry. 2008;65(12):1358-67 https://doi.org/10.1001/archpsyc.65.12.1358.

77. Beauchaine TP, Bell Z, Knapton E, McDonough-Caplan H, Shader T, Zisner A. Respiratory sinus arrhythmia reactivity across empirically based structural dimensions of psychopathology: a meta-analysis. Psychophysiology. 2019; 56(5):e13329 https://doi.org/10.1111/psyp.13329.

78. Prätzlich $M$, Oldenhof $H$, Steppan M, Ackermann K, Baker R, Batchelor M, et al. Resting autonomic nervous system activity is unrelated to antisocial behaviour dimensions in adolescents: cross-sectional findings from a European multi-Centre study. J Crim Justice. 2019;65:101536 https://doi. org/10.1016/j.jcrimjus.2018.01.004.

79. Gyurak A, Ayduk Ö. Resting respiratory sinus arrhythmia buffers against rejection sensitivity via emotion control. Emotion. 2008;8(4):458. https://doi. org/10.1037/1528-3542.8.4.458-67.

80. De Panfilis C, Meehan KB, Cain NM, Clarkin JF. Effortful control, rejection sensitivity, and borderline personality disorder features in adulthood. J Personal Disord. 2016;30(5):595-612 https://doi.org/10.1521/pedi_2015_2 9_226.

81. Rottenberg J, Salomon K, Gross JJ, Gotlib IH. Vagal withdrawal to a sad film predicts subsequent recovery from depression. Psychophysiology. 2005; 42(3):277-81 https://doi.org/10.1111/j.1469-8986.2005.00289.x.

82. Overbeek TJ, van Boxtel A, Westerink JH. Respiratory sinus arrhythmia responses to cognitive tasks: effects of task factors and RSA indices. Biol Psychol. 2014;99:1-14 https://doi.org/10.1016/j.biopsycho.2014.02.006.

83. Smith R, Thayer JF, Khalsa SS, Lane RD. The hierarchical basis of neurovisceral integration. Neurosci Biobehav Rev. 2017;75:274-96 https:// doi.org/10.1016/j.neubiorev.2017.02.003.

\section{Publisher's Note}

Springer Nature remains neutral with regard to jurisdictional claims in published maps and institutional affiliations.

Ready to submit your research? Choose BMC and benefit from:

- fast, convenient online submission

- thorough peer review by experienced researchers in your field

- rapid publication on acceptance

- support for research data, including large and complex data types

- gold Open Access which fosters wider collaboration and increased citations

- maximum visibility for your research: over $100 \mathrm{M}$ website views per year

At BMC, research is always in progress.

Learn more biomedcentral.com/submissions 